\title{
Study on the Dynamic Mechanism of Technology Transfer Institutions in China
}

\author{
Lingling Tang ${ }^{1, *}$ and Taizi Zhang ${ }^{2}$ \\ ${ }^{1}$ School of Economics and Management, Beijing Jiaotong University, Beijing 100044, China \\ ${ }^{2}$ The Twelfth Academy of China Aerospace Science and Technology Corporation, Beijing100037, China \\ *Corresponding author. Email: bjtullt@163.com
}

\begin{abstract}
The in-depth integration of technology and economy is inseparable from the services of technology transfer agencies. At present, the lack of motivation for the development of technology transfer institutions in colleges and universities in my country has profoundly affected the integration of technology and economy. By learning from the experience of developed countries, it provides a reference for the power mechanism of China's technology transfer institutions.
\end{abstract}

Keywords: Technology transfer institutions, Dynamic mechanism, Systems and mechanisms, Marketoriented reform, Person with ability.

\section{INTRODUCTION}

The international environment and domestic conditions facing China are undergoing profound changes.Facing the future,China will transform from following development to leading development.

Technology transfer institutions are the link that bridges technology and economy.It is very important to cultivate and develop my country's technology transfer institutions so that science and technology can earn money.The technology transfer institutions in this article mainly refer to internal institutions or corporate legal persons that rely on various types of legal persons such as universities and research institutes. The dynamic mechanism refers to the internal force that promotes the development of the organization.

\section{THE PROBLEM OF CHINA'S TECHNOLOGY TRANSFER AGENCY}

\subsection{Institutional and Institutional Issues}

The fundamental reason for the lack of motivation for the development of technology transfer institutions within the system is the problem of institutional mechanisms. Technology transfer institutions of colleges and universities are non-profit corporate legal persons, and the economic status of the institutions is not clear(LiuHongmin,2007). They are mostly public institutions or enterprises restructured from public institutions.

Most of the service work revolves around the functional arrangement of the competent department, and the service awareness and market awareness are not strong. This means that they cannot become the main body of technology transfer. Because the social function of the technology transfer organization in the system is to create knowledge and cultivate talents, it is to turn money into knowledge and talents, and the goal of technology transfer is to turn knowledge into money. This is the responsibility of entrepreneurs and investors. The transfer agency does not rely on technology transfer to make a living, so there is no motivation for technology transfer.

\section{2. $R \& D$ and Innovation Activities of Universities and Research Institutes are Out of Touch with Corporate Needs}

There are two main reasons for this problem. The first is that, in essence, the scientific and technological evaluation mechanism of scientific researchers focuses on quantitative indicators, especially the lack of corresponding requirements for the transformation of results, which causes scientific research activities to drift outside of market demand.The second is the inherent scientific research model, the linear thinking $R \& D$ method and the form of a guide written by experts from colleges and universities when setting up the 
project, which lacks the joint participation of enterprises(RuanYuanhua,2018).

\subsection{Intangible Asset Tax System and State- owned Asset Management System Hinder the Enthusiasm for Technology Transfer}

After the evaluation of intangible assets is completed, a piece of blank paper becomes a valuable asset, which involves the issue of value-added tax.The payment of value-added tax follows a process: first, the proceeds are distributed to the inventor in a proportion of not less than $50 \%$, and the remaining proportion of less than $50 \%$ is retained in the institution, and the institution is responsible for the full-based value-added tax Payment.Some scientific research institutes are unable to pay the value-added tax because they are too high, which leads to low enthusiasm for technology transfer in some scientific research institutes.In addition, the issue of state-owned assets of scientific and technological achievements, and the responsibility for the loss of state-owned assets seriously restrict technology transfer activities.

\subsection{Professional Technical Brokers are Lacking}

There is a widespread lack of professional talents in technology transfer institutions. Technology transfer service work is a complex task, requiring practitioners to have professional knowledge in marketing, technology, law, management, investment, etc., as well as extensive contacts and industry contacts. Many of them are engaged in technology transfer work in the United States, Japan and other countries. They are highend talents such as masters and doctors. In my country, there are relatively few compound and professional talents in the management team of achievement transformation in universities and scientific research institutions.

At present, most of the practitioners are half-way renunciations, and have not received systematic education and training in the technology transfer service business. A considerable number of practitioners have insufficient professional abilities and lack experience in the prospects of the project, resulting in a low degree of precise technical integration. There is a lack of educational mechanisms to train such talents.

\subsection{Weak Links in Technology Pilot and Maturation, Inhibiting the Promotion and Transformation of Results}

China's colleges and universities have undertaken a large number of scientific and technological projects and have achieved a large number of original scientific and technological achievements. However, there is a "valley of death" problem in the transfer and transformation of these original scientific and technological achievements.Moreover, as far as the current government science and technology funding support system and social financing ecosystem concerned,it is difficult to obtain relevant financial support during the pilot maturation stage, which has caused a large number of innovative achievements to stay in the paper and patent stage.And that largely affects the transformation of scientific and technological achievements effectiveness.

\subsection{Property Rights Incentives are not in Place}

Both theory and practice have proved that property rights incentives are the key institutional basis for promoting the transformation of scientific and technological achievements. Without property rights incentives, it is impossible to stimulate inventors' enthusiasm to promote technology transfer.From a foreign perspective, the target of technology transfer is mainly for small enterprises. Small enterprises have become the main recipients of achievement transformation because they have no R\&D capabilities.

In the absence of property rights incentives, the inventor is not enthusiastic about the follow-up of technology, and the company has no R\&D capabilities, and neither party is willing to excessively intervene in the transformation of results. The results of colleges and institutes are generally laboratory results, and companies are not dared to invest rashly because they are uncertain about future expectations, which largely hinders the efficiency of technology transfer.The most serious problem of the loss of state-owned assets in technology shares is the most serious problem. Since the ownership does not belong to the inventor, individuals dare not accept the shares of technology shares, let alone trade, and no one dares to buy them. This also caused some inventors to become underground workers.

\section{EXPERIENCE OF TECHNOLOGY TRANSFER INSTITUTIONS IN FOREIGN COUNTRY}

\subsection{Market-oriented Operation Mechanism}

Developed countries such as Germany and Israel have established relatively complete technology transfer centers (TTC), technology transfer institutions (OTL), technology transfer associations and other intermediary organizations. These organizations have gradually adopted market-oriented operation methods to promote domestic technology transfer.The German Steinbach Network is based on a flat organizational structure, and a flexible and efficient operation mechanism is established between the headquarters and the technology transfer center.Yeda in Israel is also a 
process of corporate operation and market operation(ZhaoJun,2018).

\subsection{Safeguard Mechanism of Professional Technology Transfer Team}

Technology transfer institutions in developed countries are generally small in scale. Although the number of their staff is not very large, most of them have two or more specialties in science, engineering, business and law.Quite a lot of them have a doctor's degree, and most of them have working experience in enterprises.

\subsection{Demand-oriented Mechanism}

The important difference between German and American achievements transformation is the demanddriven.German colleges and universities "provide enterprises with what they need", which is completely oriented by the needs of enterprises and provides customized services according to the characteristics of enterprises. Of course, the scope of technology transfer in Germany is much broader, including providing information consulting, marketing, process optimization, product development, cross-border transactions, etc.

\subsection{Technology Transfer Service Mechanism Based on Patent Marketing}

The American OTL model has become the standard model for technology transfer. The innovation of the OTL model lies in its self-financing business model. In addition to the initial funds provided by the school at the time of establishment, OTL relies on its own income to maintain its operation, which forces it to put patent marketing in the first place.The main way of patent marketing, namely, the main way of technology transfer, is mainly non-exclusive authorization. The target of the license is small enterprises. The royalty collection method is also flexible, such as upfront payment, annual payment, dividend, stock and so on, which effectively promotes the development of small enterprises.

\subsection{The Ownership of the Intellectual Property Rights of Publicly Funded R\&D Results is More Shifted to the Owner}

The formulation of the Bayh-Dole Act in 1980 is a milestone in the history of technology transfer in the United States(PengShulian,2008). The established "BayDole Rules" have been imitated by many countries to guide their own technology transfer work. The bill stipulates that the ownership of scientific and technological achievements funded by the federal government belongs to project undertakers, including individuals, small businesses, and non-profit organizations.It also stipulates that project undertakers have the obligation to transfer technology to effectively achieve the policy goals of Congress. Since then, Japan, Germany and other countries have turned to the "BayDole Rule", with policies suitable for their own countries, and the efficiency of technology transfer has been greatly improved.

\section{SUGGESTIONS ON PERFECTING THE DYNAMIC MECHANISM OF TECHNOLOGY TRANSFER INSTITUTIONS IN CHINA}

\subsection{Market-oriented Reform of Technology Transfer Institutions and Improvement of Market-oriented Operating Mechanisms}

The current lack of motivation for technology transfer institutions requires urgent removal of institutional barriers(GaoJiangning,2018). Innovate the technology transfer management and operation mechanism of universities and research institutes. The management system and mechanism must adapt to market-oriented reforms. At the same time, establish a market-oriented salary distribution system, performance evaluation mechanism, selection and employment mechanism, marketing incentive mechanism and other institutional mechanisms that fully mobilize the enthusiasm of employees.

\subsection{Establish Performance Evaluation for Technology Transfer Personnel and Improve the Safeguard Mechanism of Talent}

One is to establish a performance evaluation system for scientific and technical personnel engaged in technology transfer.Break the thinking of research-only and thesis-only.Treat technology transfer activities the same as scientific research and papers, and also serve as the standard for the promotion of scientific and technical personnel.

The second is to establish a professional title system for technology transfer professionals, which can learn from the mature technology brokers at home and abroad.According to the actual requirements of the technology market for the development of technical brokers, formulate standardized technical broker management regulations to promote the development and growth of the technical broker team(LiuHaoyang,2018). 


\subsection{Learn from the New Organizational Model of Developed Countries to Solve the Problem of "Valley of Death", and to Strengthen the Promotion Mechanism of Pilot and Maturation}

Encourage pilot projects for the construction of proof-of-concept centers.The government should encourage and support domestic research universities to go to the proof-of-concept centers of well-known American universities to conduct investigations and research.In-depth study of the development history, main features, development model and incentive mechanism of the construction of proof-of-concept centers in American universities. Combining its own reality, explore the development path of the construction and development of a unique concept verification center.

\subsection{Promote the Reform of Scientific Research Mode and Improve the Demand-oriented Mechanism}

Establish a technological innovation system with enterprises as the main body, market-oriented and indepth integration of production, education and research.Innovate scientific research models, establish a basic scientific research system of "walking on two legs", establish a market-oriented and enterprise-based basic system, and explore the establishment of a new nationwide system for key core technologies.Establish a market-oriented high-quality technology research and development system and system, and improve the market awareness of research and development institutions and technology transfer institution.

\subsection{Reform of Mixed Ownership of Job Science and Technology Achievements}

Ownership of scientific and technological achievements is the core right of scientific and technological achievements and the basis of other rights (rights of income, use rights, etc.). The mixed ownership reform of ownership is currently the most difficult to implement and the most prudent. It involves all aspects of risks and benefits. If there is a major breakthrough in this point across the country, it will push the achievement transformation model to a new level.

\section{CONCLUSION}

China is facing major changes unseen in a century, and the role of technology transfer institutions in promoting the deep integration of technology and economy is becoming more and more prominent. At present, China's technology transfer institutions have problems such as system and mechanism problems, insufficient R\&D demand orientation, institutional obstacles, and lack of talents. Based on the development experience of foreign technology transfer institutions and combined with China's actual conditions, it is found that Chinese technology transfer institutions need institutional reforms and scientific research, improvement of the performance evaluation system, the development of new technology transfer institutions, and the reform of scientific research models to meet the urgent needs of high-quality economic development, and to increase the contribution rate of science and technology to the economy.

\section{AUTHORS' CONTRIBUTIONS}

The article is mainly completed by the first author. Thanks to the second author for his research work.

\section{ACKNOWLEDGMENTS}

We are grateful to an anonymous referee.Thanks to everyone who helped us during the writing process.

\section{REFERENCES}

[1] LiuHaomin, YangYandong.The role of university science and technology intermediaries in technolo -gy transfer and development ideas[J].Research and Development Management,2007(05):133-137.

[2] RuanYuanhua,XuXiaoan.Analysis on the Technology Transfer and Transformation Mode of New R\&D Institutions from the Perspective of Collaborative Innovation-Taking the Cloud Computing Center of the Chinese Academy of Sciences as an example[J].Science and Technology Innovation Development Strategy Research,2018,2(03):85-88.

[3] ZhaoJun.The Experience of Germany and Israel for Reference to the Transfer of Guangdong's Scientific and Technological Achievements[J].New Economy,2018(04):38-42.

[4] GaoJiangning.Research on the Construction Path and Development Strategy of University Technology Transfer Institutions_-Based on the Comparative Perspective of German Technology Transfer Institutions[J].China Science and Technology Industry,2018(10):75-77.

[5] PengShulian,XiaoGuofang.The Path Analysis and Enlightenment of Stanford University Technology Transfer[J].Modern Education Science, 2008(03).47-50.

[6] LiuHaoyang.Research on the New Trends of the Construction and Development of University Technology Transfer Organizations[J].Chinese and Foreign Entrepreneurs,2018(18):171. 